\title{
BREVE ANÁLISE DE NARRATIVAS LITERÁRIAS DIGITAIS
}

Cláudia Grijó Vilarouca ${ }^{1}$

Foi um passo longo no tempo para que as narrativas orais fossem paulatinamente passando para o registro escrito, sem que aquelas deixassem de existir. Menos tempo foi preciso de um para que narrativas do meio impresso transitassem também para outro meio, o digital.

Com esse novo suporte, novas possibilidades se abrem para o texto literário com a experimentação de outros recursos, porém, é preciso refletir sobre até que ponto essas possibilidades modificam aquilo que chamamos de literatura, se aquilo que temos visto no meio digital é, de fato, substancialmente diferente daquela literatura realizada por autores mais audazes, que se propuseram a explorar o máximo da linguagem e do modo de contar (considerando aqui a narrativa). E ainda, se considerarmos que se trata de literatura, em que ela se diferencia verdadeiramente daquela produzida em meio impresso.

Primeiramente, vou partir de uma concepção simples de literatura que servirá de pressuposto para essa análise. A literatura está intrinsecamente associada à palavra, à littera, seja ela oral ou escrita. Por essa razão, a narrativa da qual se quer tratar aqui é da literária, que além de se constituir por palavras (sejam orais ou escritas), pertence ao campo ficcional. Por exemplo, a narrativa da Paixão de Cristo, amplamente representada pictoricamente na Idade Média devido à escassez de um público letrado, tornou-se importante para que os que não sabiam ler tivessem acesso aos ensinamentos da Igreja, como afirmava o Papa Gregório Magno, no fim do séc. VI: "a pintura pode fazer pelos analfabetos o que a escrita faz pelos que sabem ler" (GOMBRICH, 2008, p.135). Essa narrativa possuía uma função religiosa. Esse é um tipo de narrativa que pertence ao campo das artes visuais ou plásticas. No caso da narrativa literária, outros procedimentos são requeridos tanto do autor como do leitor. Da parte do autor, o uso premeditado da linguagem falada/escrita e, considerando aqui os procedimentos clássicos de construção de narrativa, a elaboração de um enredo minimamente coerente ${ }^{2}$ com seus personagens, ações, espaço-tempo. Ao leitor é solicitado certo de tipo de adesão ao modo como o autor explora a língua, é preciso o reconhecimento de que ali há um pensamento sobre a linguagem escrita (ou oral) que perpassa a história narrada. A língua não é apenas o meio

\footnotetext{
${ }^{1}$ Doutoranda em Teoria Literária do Programa de Pós-Graduação da Universidade Federal de Santa Catarina. Membro do Núcleo de Pesquisa em Informática, Literatura e Linguística. claudia.vilarouca@gmail.com

2 Finnegans Wake é um exemplo que foge a esse padrão.
} 
para alguma finalidade artística e sim a própria matéria para o dizer artístico, assim como a cor ou o relevo são para as artes visuais, o som o é para a música.

Ocorre que no meio digital a inter-relação de diferentes linguagens, muito mais explorada que no impresso (quando associa desenhos, gravuras, por exemplo, aos textos), faz com que pensemos que algo totalmente novo, que uma literatura diferente teria surgido. Até que ponto podemos assim considerar?

\section{Novos caminhos para a narrativa}

É difícil falar em modelos de narrativa após algumas obras de Joyce, de Perec, Calvino, e de Cortázar, entre outros, que no século XX mostraram que ainda há muito por experimentar.

Apesar dessas inovações concernentes às estruturas narrativas, grande parte ainda pode ser analisada à luz das categorias mais tradicionais (personagens, enredo, intriga, tempo-espaço, foco narrativo) no sentido de que ainda se pode falar nelas. Os autores que acabo de citar exploraram o potencial da narração propriamente dita, não apenas quanto à linguagem, mas quanto à estrutura, composição do texto. Daí a confusão de uma parte da crítica que denomina algumas de suas obras de "anti-romance", por exemplo, quando na verdade se trata de uma mutação em alguns componentes do gênero. O que nos chama a atenção é o modo de narrar que vai exigir do leitor um modo distinto de operar (a leitura).

Com efeito, não me parece que essas categorias tenham se alterado a ponto de falarmos em outro gênero. Muito do que vemos como sendo "hiperficção" é narrativa. O que se percebe é uma integração entre linguagens que apelam mais fortemente para o sensorial e que exigem certo tipo de interatividade material que não era comum em obras literárias no meio impresso. Pode ser que se crie uma rede de significantes muito mais ampla que demande processos de organização da narrativa mais complexos, dependendo do grau de significação a qual se almeja alcançar. Nem sempre isso ocorre, pois essa integração não necessariamente se justifica, nem sempre foca no artístico e acaba sendo mais uma "bonificação ao olhar", para usar a palavra que Miguel Rettenmaier (CORRÊA, 2008, p.77) usa $^{3}$, ou seja, nem sempre o uso da imagem, do som, vinculados ao texto, irão de fato enriquecê-lo, parecendo muito mais um exibicionismo técnico - utilizando-se de todos os recursos possíveis - do que uma necessidade da própria narrativa

\footnotetext{
${ }^{3}$ Rettenmaier refere-se à literatura infanto-juvenil com suas "bugigangas" com o intento de seduzir os jovens leitores, enfim, aparatos multimídias que não aproximam o leitor do texto, mas que em muitos casos trata-se "nos piores casos, como um atrativo de um pequeno fetiche consumista". Cf 2008, p.77.
} 
Para além dessa consideração, é importante mencionar como se dá a interatividade nessas obras. O tema foi bem trabalhado por Otávio G. Tavares (2010), concernente à poesia. Todavia, alguns aspectos da interatividade no meio digital que o autor expõe podem ser pensados também para a narrativa. Entre eles,

a interação material é um fator necessário para a construção de sentido. Poderíamos dizer que a efetiva manipulação do leitor faz parte de um programa - série de regras - proposto na obra, um modo de ler que está previsto na estrutura daquele objeto e sem o qual o leitor não conseguirá ler a obra. (TAVARES, 2010, p.29)

Ou seja, a materialidade é significante. É da manipulação dessa materialidade que tornará possível vislumbrar as significações da obra.

Outro aspecto relevante é que "a leitura se apresenta como um ato que necessita reaprender os seus limites e caminhos e captar as possibilidades do objeto. Não podemos iniciar nossa leitura interpretando o texto, mas constituindo um modo de leitura" (2010, p.32). O leitor deve se acostumar com todo o aparato tecnológico a sua frente para poder se embrenhar nesses caminhos a fim de explorar o objeto literário.

Além do mais, uma possível característica das narrativas literárias digitais é que dificilmente elas sobreviverão mais de 50 anos. A transitoriedade do suporte acaba tornando a própria narrativa transitória, no sentido de que ela tende a desaparecer. A rápida mudança e melhoria do meio levam à inadequação do antigo, apesar de emulável para quem sabe operar. Entretanto, muitas vezes fica perdido por completo (o meio digital, além de fluído, tem muito de efêmero, o que não é novidade para ninguém). Como nas obras de arte contemporâneas, que despontam nas grandes bienais e não restam mais que vestígios nos registros fotográficos ou de vídeo. É um evento.

É preciso contar com os recursos utilizados numa mesma época - assim como para nós é difícil ler um texto manuscrito do século XVI, por exemplo: a morfologia das palavras sofreu alteração; os caracteres vão nos parecer estranhos. Um leitor que se depara com uma narrativa realizada no século XVIII, por exemplo, também poderá ser acometido por um estranhamento - mais ainda no meio digital, cuja instabilidade, a torrente de modificações, de novos recursos lançados a cada ano, indicam que sua duração é curta (se compararmos com a duração de uma narrativa impressa em boas condições de armanezamento $)^{4}$.

\footnotetext{
${ }^{4}$ No digital passamos de um problema meramente interpretativo para um problema operacional físico (a narrativa é quase um programa, algumas o são efetivamente).
} 


\section{Algumas narrativas literárias digitais}

É comum falar de narrativas literárias digitais abrangendo os vários tipos de textos literários compostos no e para o meio digital, usando vários tipos de mídias que apenas o meio digital pode proporcionar.

Eis também o porquê de ser tão difícil se livrar das categorias tradicionais narrativas, e isso vale tanto para os criadores quanto para os críticos ao analisarem tais obras. As mudanças apontam mesmo para o modo como se conta e pelas formas de interatividade (do lado do leitor) - e esta pode ser umas das chaves, mas não a única, para se pensar a diferença entre a narrativa do meio impresso e a do meio digital.

A interatividade do leitor no meio digital dá a ilusão de haver muitas ${ }^{5}$ possibilidades, tornando o leitor "livre". Nem tanto. A mão do autor está bem presente, afinal, a narrativa precisa de limites, no sentido de que ela possui um número de possibilidades, de texto, enfim, de recursos, estipulado previamente pelo autor, ainda que fique em aberto e suas combinações conduzam a uma infinidade de significações. De qualquer maneira, como expus anteriormente, há certas categorias das quais não se pode prescindir: a narrativa, para ser literária, ainda necessita de certos aspectos: dos personagens, de um narrador, de espaço-tempo (embora este último termo possa estar em suspenso).

Falarei um pouco de três narrativas literárias digitais, uma de língua espanhola, uma francesa e uma brasileira, refletindo sobre esses aspectos que compõe a narrativa propriamente dita.

\section{GOLPE DE GRACIA}

"Golpe de Gracia" é uma criação de Jaime Alejandro Rodríguez, da Universidad Javeriana de Bogotá, de 2005, que integra narrativa literária, jogo e até mesmo crítica (na parte em que há sala de estudos).

Há um arquivo, na página da obra, que consiste na história propriamente dita, a parte textual (que é uma novela intitulada $\mathrm{O}$ inferno de Amaury), que pode ser baixada em pdf e impressa. Apesar de ser um trabalho que se utiliza de muitas mídias, fica claro que a história pode ser lida prescindindo do meio digital.

\footnotetext{
${ }^{5}$ Hoje em dia temos a possibilidade de criar obras de arte com possibilidades não explicitamente calculáveis, no entanto, devemos lembrar que maioria das narrativas digitais deriva de uma época em que tais possibilidades não eram bem acessíveis, logo, maioria são construídas com limites materiais (apesar de aparentemente grandes) bem estipulados.
} 
Essa hiperficção contém jogos cujo objetivo seria um aprofundamento do caráter e da ação do protagonista, tem sala de estudos (com "multiblogs" tratando das temáticas envolvidas na criação: velhice como metáfora de decadência; lendas da Galícia (no jogo da Costa da morte); ciberanarquia/hikikomori (em japonês, sujeito que vive isolado, um "ermitão do séc. XX", representado por Angel Maldonado, o rapaz que arma o atentado contra o protagonista), entre outros; possui uma parte de construção sob a forma de wiki, que convida os leitores a elaborarem reflexões para se compreender melhor o fenômeno da cibercultura e tudo que está relacionado a ela; a parte de leitura, que são textos que constituem a narrativa e que vão esclarecendo e/ou aprofundando aspectos da personalidade do personagem principal, de circunstâncias de sua vida, lembranças etc. Enfim, é uma descrição bem geral da obra

Nessa hiperfição há várias vozes narrativas. De certo modo, é como se esse papel o de narrador - fosse repassado ao leitor também, para que ele 'monte o quebra-cabeças' que o criador lançou. Ao mesmo tempo, é interessante notar que a narrativa é comum e segue todos os padrões como apontou Edgar Kirchof:

A crônica revela a estrutura narrativa de Golpe de gracia, e de modo surpreendentemente linear. Trata-se de uma história extremamente simples, cujas principais seqüências - explicitadas ou não no plano da enunciação - podem ser dispostas facilmente a partir do esquema quinário clássico: 1) situação inicial (o padre Amaury encontra-se bem); 2) conflito ou perturbação (alguém atenta contra a vida do padre); 3 ) desenvolvimento (as tentativas do repórter/leitor/navegador para desmascarar o vilão); 4) desfecho (a descoberta do vilão); 5) situação final (tudo o que sucede com o padre e o vilão após o desfecho). (KIRCHOF, 2009)

Ademais, os personagens se mantêm lineares também, sem grandes transformações. A mudança de Amaury - o protagonista, vítima do atentado - para reparar os erros, é apenas sugerida.

O tempo-espaço se torna mais complexo, porém, eu não diria que é por causa do meio em que a narrativa se encontra. Visto que o personagem principal vive a experiência da morte, que há "vozes" do outro lado da vida, de fato há uma quebra, por um lado, desse aspecto espaçotemporal.

Embora seja evidente (e louvável) o empenho do autor em elaborar uma narrativa literária que contemple várias mídias e, mais ainda, fazer o leitor experimentar junto com o protagonista um estado de incerteza quanto à continuidade da vida, angústias e lamentos, há alguns problemas. O primeiro deles é que essa narrativa não nasceu no meio digital. 
Explico-me melhor. Disse há pouco que o autor disponibilizou o texto da novela. Ou seja, primeiro a novela foi criada - podendo ter sido manuscrita ou digitalizada no Word, pouco importa - para depois ter sido trabalhada no meio digital, tendo sido "levada" para esse meio. Uma narrativa criada no meio digital só pode ser lida, apreciada, nesse meio.

Outro problema diz respeito ao manuseio de "Golpe de Gracia" e que é consequência do primeiro: a narrativa fica desconjuntada, quebrada mesmo. As novas gerações, sobretudo as oriundas das classes média e alta, mal saem do berço e já entram em contato com o mundo digital. Um jogo como World of Warcraft, apesar de não ser propriamente uma narrativa literária, chama muito mais a atenção de um usuário adicto da internet, devido aos desafios que oferecem.

Deixo claro que não estou menosprezando a obra de Javier, que penso ser de ótima qualidade. O que está em discussão é o estatuto de uma narrativa literária digital, seus elementos, características, diferenças. Incomoda o pensamento assaz difundido - inclusive por teóricos - da novidade, em todos os âmbitos da vida, como uma praga que assola alguma lavoura. Quero dizer com isso que, de repente, se fala em "novo gênero" de literatura, quando na verdade, há muito mais para se discutir, refletir, ponderar.

\section{ESTUDO EM VERMELHO}

Um estudo em vermelho, de Marcelo Spalding, é um hiperconto que narra a história de um rapaz, cuja irmã desapareceu. Ambos são herdeiros de uma grande fortuna. Seus pais faleceram no recente acidente da Air France na costa do Nordeste. Os motivos do desaparecimento da irmã, que podem ser um sequestro, uma trama de amor e ambição, fuga, dão o tom da narrativa. Há 8 possibilidades de terminar a história, dependendo das combinações de escolhas que o leitor faz. O interessante aqui é que os personagens se cambiam de acordo com as escolhas que o leitor empreende. Há mudanças de comportamento, consequentemente, de caráter, entre outros. Na verdade, nesse caso, temos várias narrativas possíveis a partir de um começo. Algo similar ao que fez Julio Cortázar em "Rayuela" (Jogo da Amarelinha), cuja leitura pode ser feita seguindo o caminho por ele estipulado ou seguindo sequencialmente página a página. No conto "Estudo em vermelho" não há uma sequência como no formato de um livro. Nesse sentido, é uma obra que aproveita os recursos para oferecer ao leitor modo diferente de lidar com a narrativa. Spalding nos diz que: 
hiperconto seria uma versão do conto para a Era Digital. Sendo ainda um conto, de tradição milenar, requer narratividade, intensidade, tensão, ocultamento, autoria. O texto, naturalmente, ainda deve ser o cerne do hiperconto, preservando seu caráter literário. Mas um bom hiperconto será capaz de aproveitar as ferramentas das novas tecnologias para potencializar a história que conta da mesma forma que os livros infanto-juvenis, por exemplo, têm se utilizado da ilustração. Imagens, em movimento ou não, áudios, hiperlinks, interatividade e quebra da linearidade são apenas algumas das possibilidades do hiperconto (SPALDING, 2009).

Esse comentário remete ao que Landow diz do hipertexto ou ao que comumente se diz de qualquer literatura do meio digital, mas me parece que ela é uma forma que "adiciona" coisas ao o conto ou romance normal, pelo menos parece que existe uma ideia de "acrescentar" ou utilizar, quando me parece que deve haver uma construção já na obra.

Apesar de possuir uma forma tradicional das narrativas policiais, nesse hiperconto, fica mais claro aquilo que afirmei acima, de que o leitor faz o papel do narrador, não no sentido tradicional do termo - e digo narrador por não encontrar outro melhor no momento - mas sim no sentido de organizar a narrativa. Isso é bem diferente de tornar o leitor um escritor, do qual tratarei mais adiante.

NON, um romance multimídia de Lucie de Boutiny começou a ser publicado na revista Sinesthésie, a partir do ano de 1997 a 2000, editado por episódios. Compõe-se de 6 capítulos, cujo elo não é nada evidente. Os personagens não são caracterizados. Não há uma ação propriamente dita ou um ou um conflito anunciado. A tensão no andamento do romance depende do estabelecimento de um fio condutor na narrativa que fica a cargo do leitor. Muitas são as ligações: desde slogans publicitários, minicontos, muitos ícones, fundo de tela (chega mesmo a ser um poluído), conversas virtuais, propostas de produtos (como se o leitor fosse cliente), reflexões sobre política, consumo, entre outros, que nos conduzem a uma dinamicidade narrativa com todo um entorno complexo, alterando a percepção da história - ou de pedaços dela - de um clique a outro. Os sentidos são extremamente moventes e novamente o leitor tem que se tornar um narrador se quiser apreender essa história. Do contrário, são apenas linques, espaços-tempo fragmentados.

Aqui temos um exemplo bem mais complexo de elaboração de narrativa, que a autora chama de romance. Esta é uma obra que não poderia de modo algum ser transposta para o meio impresso, pois ela só pode existir no meio digital, não apenas por usar seus 
recursos, mas por conter em si o modo de ser digital que significa ter uma linguagem própria que existe somente no meio digital. Trata-se de um romance multimídia que explora bem todos os recursos que o meio eletrônico pode oferecer. Sendo assim, a fluidez e imprevisibilidade, como nos diz Alckmar dos Santos, próprias do texto - não importando em que meio se insere - são potencializadas: "[a]quilo que no texto é intertextualidade, no livro eletrônico encontra correspondência na pluralidade de percursos e na heterogeneidade de materiais (associações de matéria verbal, imagens, sons etc)." (SANTOS, 2003, p.22).

\section{Criador $\mathrm{x}$ leitor}

Há certos discursos que preconizam o fim dos grilhões que o artista/autor impõe ao leitor. Desde Barthes, com o famoso texto "A morte do autor" - que me parece uma tentativa de dar legitimidade para a crítica e até mesmo de colocá-la no mesmo patamar de criação que o escritor de literatura. Algo semelhante ocorreu (e ainda ocorre) com a leitura de "A Obra Aberta" de Umberto Eco, escrita anteriormente (de 1962-63) ao texto de Barthes, que, segundo me chegam ainda hoje aos ouvidos, foram compreendidos não raras vezes como se o autor tivesse sido colocado em uma espécie de "banco dos réus" porque é autoritário, tirano, egoísta. O mundo digital seria a solução para que o leitor participe 'democraticamente' da criação da obra - em oposição a uma literatura impressa em que o leitor estaria "preso" às amarras do autor. O problema dessa visão é que ela cria uma dicotomia que nada acrescenta à leitura crítica da obra (torna-se quase uma luta partidária).

Não para por aí. Esse discurso nos leva a outra tirania, a do leitor. Em se tratando de arte, há um acordo tácito entre coisa percebida e aquele que a percebe, entre o objeto artístico e aquele que o usufrui. Não dá para dizer que Igor Stravinsky(1882-1971) era um tirano porque nos obrigava a ouvir certo grupos de notas que compunham a melodia de Pássaros de Fogo; também não podemos acusar Picasso de nos submeter àquelas cores e formas bidimensionais das Mademoiselles de Avignon. Enfim, podemos exemplificar como um sem número de obras. Se não se quer a "submissão" ao autor, então por que querer estar diante da sua obra, escutá-la, vê-la ou lê-la? Claro que tais obras não existem sem o ouvinte, espectador e leitor, mas daí a impor sua participação na obra - e isso tem ficado mais evidente na literatura - já é ser autoritário também.

Fala-se em tornar o leitor escritor, algo que ele nunca será de fato, quando se trata de obras interativas pois há todo um programa estipulado pelo programador e TODAS as 
opções que o autor propõem são mais ou menos propostas em potencial. Como na televisão, quem não lembra do "Você decide?", programa de narrativas policiais, em que o espectador escolhia o final telefonando para a emissora, dada duas opções. Acontece que no meio digital temos mais possibilidades, daí a ilusão de que o leitor é livre e de que ele "escreve" a obra. Falo de escrever aqui em sentido "estrito". O que ocorre, isso sim, é a ampliação de horizonte de sentido da obra, visto que ela possibilita o leitor traçar diferentes vias de elaboração de sentido. Porém, esses sentidos possíveis foram pensados pelo autor/criador, ainda que eles não possam prever completamente todos eles.

\section{Considerações finais}

Apesar de meu interesse em pesquisar mais e compreender as narrativas literárias digitais, é patente a pouca produção delas, sobretudo no Brasil. Mesmo no Estados Unidos em que essas narrativas tiveram um maior sucesso, chegando até mesmo a ter um portal para sua comercialização, percebe-se um recuo. Mais leitores eram esperados, porém, não foi o que ocorreu.

Poder-se-ia pensar que os tablets talvez proponham uma saída e haja uma retomada na produção de narrativas literárias digitais; contudo, sendo que maioria deles está vinculado a uma empresa, é possível que a produção desse tipo de narrativas será tão somente um produto a mais, um atrativo a mais destinado a público alvo determinado. E aí duvido de uma preocupação com uma qualidade literária desses produtos.

De qualquer modo, a facilidade de manuseio desses aparelhos poderia ser um chamado para mais leitores do meio digital, porém, não me parece que a problemática esteja ligada ao suporte propriamente dito. Observa-se que as narrativas mais difundidas atualmente sejam aquelas que nascem nos blogs, narrativas no meio digital, apreciadas por muito seguidores. Narrativas que, em princípio, atraem em parte por serem atribuídas a "pessoas comuns", existentes na "vida real, com as quais se pode interagir em tempo real. Sem dúvida, a dificuldade do suporte se impõe, visto que nem todos que desejam se aventurar na produção de narrativas digitais possuem o conhecimento necessário da programação a fim de aproveitar todos os recursos disponíveis; ou não têm uma equipe com a qual possam contar. $\mathrm{Na}$ verdade, não importa aqui elencar uma série de hipóteses do porquê da escassa produção de narrativas literárias digitais, mas sim de refletir que tipo de escrita, de narrativas têm se expandido, tem multiplicado seus leitores? Lembrando das 
chamadas hiperficções colaborativas que também não vingaram, arriscaria a dizer que o leitor de hoje não se pretende criador, mas sim leitor crítico e/ou à espera de uma narrativa que possa ser indentificada com a sua própria.

\section{BIBLIOGRAFIA}

CORRÊA, Alamir Aquino (org.). Ciberespaço: mistificação e paranoia. Londrina: Universidade Estadual de Londrina, 2008.

GOMBRICHT, E.H. História da arte. (trad. de Álvaro Cabral). Rio de Janeiro: LCT, 2008.

KIRCHOF, Edgar. Narrativa digital: un nuevo estilo literário?. In: IV Congreso de la Cibersociedad, 2009.

http://www.cibersociedad.net/congres2009/actes/html/com narrativa-digital-un-nuevoestilo-literario 1019.html\#sdfootnote1anc

SANTOS, Alckmar Luiz dos. Leitura de nós: ciberespaço e literatura. São Paulo: Itaú Cultural, 2003.

SPALDING, Marcelo. $\mathbf{O}$ hiperconto e a literatura digital. http://www.digestivocultural.com/colunistas/coluna.asp?codigo=3034, 2010.

TAVARES, Otávio Guimarães. A Interatividade na poesia digital. 1v. Dissertação (Mestrado) - Universidade Federal de Santa Catarina, Centro de Comunicação e Expressão, Programa de Pós-Graduação em Literatura, Florianópolis, 2010.

\section{SITIOGRAFIA}

http://www.hiperconto.com.br/estudoemvermelho/

(Marcelo Spalding, 2009) Acessado em novembro de 2010.

http://www.javeriana.edu.co/golpedegracia/

Acessado em novembro de 2010.

http://www.synesthesie.com/boutiny/\#

("NON" roman, de 2001) Acessado em outubro de 2010. 